\title{
The correspondence between persistent self-reported post-traumatic problems and general practitioners' reports after a major disaster
}

\author{
ANNELIEKE N. DROGENDIJK ${ }^{1}$, ANJA J. E. DIRKZWAGER ${ }^{2}$, \\ LINDA GRIEVINK ${ }^{3}$, PETER G. VAN DER VELDEN ${ }^{1 *}$, \\ FRANS G. H. MARCELISSEN ${ }^{1}$ AND ROLF J. KLEBER ${ }^{1}$ \\ ${ }^{1}$ Institute for Psychotrauma (IVP), Zaltbommel, The Netherlands (in collaboration with Utrecht University); \\ ${ }^{2}$ Netherlands Institute for Health Service Research (NIVEL), Utrecht, The Netherlands; ${ }^{3}$ Center for \\ Environmental Health Research, National Institute for Public Health and the Environment (RIVM), Bilthoven, \\ The Netherlands
}

\begin{abstract}
Background. Little is known about the correspondence between persistent self-reported disasterrelated psychological problems and these problems reported by general practitioners (GPs). The aim of this study is to analyse this correspondence and to identify the factors associated with GPs' detection of persistent psychological problems.
\end{abstract}

Method. This study was conducted in a sample of 879 adult disaster-affected victims, taken from two longitudinal sources: the Enschede Firework Disaster Study and the GP-Monitor Study. Participants filled out a questionnaire 2-3 weeks and 18 months post-disaster and these data were combined with data from a GP-monitor collected up to 18 months post-disaster. The correspondence between persistent self-reported and GP-reported psychological problems was analysed with cross-tabulations. Logistic regression analyses were performed to identify variables which predicted GPs' detection of psychological problems.

Results. The correspondence rate among victims who visited their GP 18 months post-disaster was $60.4 \%$ for persistent intrusions and avoidance reactions, $72.6 \%$ for persistent general psychological distress and less than $20 \%$ for persistent depression and anxiety symptoms or sleep disturbances. Characteristics that predict GPs' identification of post-traumatic reactions or psychological distress were the level of self-reported post-traumatic symptoms/mental health, the number of contacts the victims had with their GP and the level of the victims' disaster-related experiences.

Conclusions. In general, there is a considerable correspondence between GP-reported and persistent self-reported incidences of post-traumatic stress and general psychological distress in disasteraffected victims. However, the correspondence declines in the case of more specific psychological symptoms.

\section{INTRODUCTION}

Characteristic psychological reactions after disasters and other extreme events are intrusions and avoidance reactions, as described

* Address for correspondence: Peter G. van der Velden, Ph.D., Institute for Psychotrauma, PO Box 266, 5300 AG Zaltbommel, The Netherlands.

(Email address: peter.vdvelden@ivp.nl) by cognitive theories on trauma (Brewin \& Holmes, 2003; Creamer, 1995; Horowitz, 1976). In addition to these post-traumatic reactions victims may suffer, for instance, from depression, anxiety, hyperarousal and physical symptoms (Başoğlu et al. 2004; Galea et al. 2005; Norris et al. 2002). If these reactions are persistent, a post-traumatic stress disorder 
(PTSD) may develop in time. Co-morbidity of this disorder with other disorders (e.g. depression, substance abuse) is often large (Breslau et al. 2000). In most cases a (considerable) minority of surviving victims will develop these disorders (Breslau et al. 1998; Galea et al. 2005).

In order to receive treatment for posttraumatic disturbances many disaster-affected people will first visit their general practitioner (GP) (Yang et al. 2003; Yzermans et al. 2005). In some European countries, such as The Netherlands and Denmark, a GP functions as the central gatekeeper for more specialized mental health care (this function is regulated by law): if necessary, the GP will refer patients to specialized mental health services. However, after the 11 September 2001 terrorist attacks in New York up to $64 \%$ of the persons with probable PTSD or depression did not seek professional help in the first 6 months (Stuber et al. 2006).

In this context the patients' presentation or GPs' recognition of disaster-related problems is a key issue. Since post-traumatic stress disorders can be cured - evidence-based (short-term) interventions are available for PTSD and treatment may lead to a lower prevalence of PTSD in the long term (Başoğlu et al. 2005; Foa et al. 2006) - it is of the utmost relevance that disaster-affected victims with mental health disturbances do receive specialized help.

In general, GPs are regularly confronted with patients who experienced traumatic events (Del Piccolo et al. 1998; Akker et al. 2001; Mol et al. 2002). Research among a general population showed that $28 \%$ of victims of traumatic experiences preferred some form of help for their post-traumatic problems (Mol et al. 2002). Many studies have been conducted which examined GPs' recognition of depression in the general population. GPs successfully detected depressive symptoms in (only) 36-62\% of patients from the general population, who had reported severe depressive symptoms on a questionnaire or in a clinical interview (Van der Pas \& Verhaak, 1998; Kessler et al. 1999; Borowsky et al. 2000; Saltini et al. 2004).

Consequently, an important issue concerns which people with mental health problems are detected by the GP and which are not. Several studies determined the characteristics of people whose mental health problems were detected by a GP. Persons with high scores on self-report questionnaires were best recognized (Borowsky et al. 2000; Bower et al. 2000; Thompson et al. 2001; Nuyen et al. 2005). Sociodemographic variables are also associated with detection. Some studies in the UK and USA found that ethnic minorities with mental health problems were more at risk of not being detected (Borowsky et al. 2000; Bhui \& Bhugra, 2002) while other studies did not (Bhui et al. 2001; Maginn et al. 2004). The study of Nuyen and co-workers (2005) found that a low educational level significantly increased the risk of underdiagnosis.

Furthermore Borowsky et al. (2000) found that men (from the USA) were at risk of non-detection while the studies of Bhui and colleagues (2001) and Maginn and co-workers (2004) found that (British) women were less well detected than men. However, the study of Del Piccolo and colleagues (1998) showed that (Italian) women shared their traumatic experiences more with their GP, particularly when they had known their GP for a long time.

Finally, physicians were less likely to detect mental health problems in patients younger than 35 (Borowsky et al. 2000) whereas older patients were more likely to be recognized (Bower et al. 2000; Thompson et al. 2001). Such a difference can also be explained by the fact that visits of patients older than 45 lasted significantly longer than those of younger patients, even when controlling for physical health status (Callahan et al. 2000). Furthermore, Del Piccolo and co-workers (1998) showed that the elderly were more likely to find it appropriate to confide in their GP. In contrast, Maginn and colleagues (2004) reported no significant relationship.

Few (empirical) studies focused on using GP information of disaster-affected victims suffering from post-traumatic stress (Donker et al. 2002). Donker and colleagues (2002) found in a sample of victims affected by a plane crash in The Netherlands that three-quarters of the selfreported physical and psychological symptoms (6 years after the disaster) were reported to the GP. Interestingly, victims attributed their symptoms more to the disaster than did their GP (Donker et al. 2002).

The first aim of the present study is to assess the correspondence between persistent 
self-reported post-traumatic stress responses and mental health problems on the one hand and the GPs' detection of these problems on the other. Furthermore, we examined which patients were more likely to be identified by their physicians as suffering from persistent post-traumatic stress or mental health problems. In this paper we will focus on persistent symptoms, i.e. self-reported problems $2-3$ weeks and 18 months post-disaster.

In this study, data are combined from two main sources: a longitudinal health survey in the disaster-affected community and a GP-surveillance study of disaster-affected patients.

\section{METHOD}

\section{Background}

On 13 May 2000 a major disaster occurred in the city of Enschede (152000 inhabitants) in The Netherlands. The disaster started with exploding fireworks in a fireworks storage and trade company. The company was situated in a residential area and due to the massive explosion the disaster severely damaged or destroyed about 500 houses. Twenty-three persons were killed and over 900 people were injured. The Dutch government declared it a national disaster and launched a comprehensive healthsurveillance (Roorda et al. 2004).

\section{Procedures}

Part of this health surveillance was the Enschede Fireworks Disaster Study (Van Kamp et al. 2005; Van der Velden et al. 2006a,b). At T1, 2-3 weeks post-disaster, affected residents were asked by mail to participate. Furthermore, the study was announced in the local press to encourage affected residents to participate. In October-December 2001 (18 months postdisaster: T2), participants who gave their written informed consent at $\mathrm{T} 1$ were asked to participate again.

Another element was the GP-surveillance (Yzermans et al. 2005). Recordings of symptoms and diagnoses by GPs in electronic medical records (EMRs) established before the disaster were maintained throughout the research period (until 1 December 2001) and were used to monitor health problems. For each patient, all contacts and individual diagnoses were registered. All information on symptoms and diagnoses was classified according to the International Classification of Primary Care (ICPC-2, 1998; Lamberts \& Woods, 1987). In the city of Enschede, $44(73 \%)$ out of 60 GPs participated, and $89 \%$ of all disaster victims appeared to be registered with these participating GPs.

Finally, the databases of the Enschede Fireworks Study and this GP-monitor were combined. In accordance with Dutch law a detailed set of rules and regulations to protect the privacy of the respondents was followed, which had been approved by the Dutch Data Protection Authority. Participants in this study were 18 years or older during the disaster and were registered with a GP at least until 18 months post-disaster.

\section{Measures}

\section{Questionnaire}

Participants filled in an extensive questionnaire at $\mathrm{T} 1$ and $\mathrm{T} 2$. The questionnaire contained several standardized questions about their educational level (for this study dichotomized in $1=$ primary or junior high school, $2=$ senior high/vocational education/university), ethnicity ( $1=$ Dutch native, $2=$ immigrant $)$ and gender ( $1=$ male, $2=$ female $)$.

At $\mathrm{T} 1$ disaster exposure was investigated by a list of 21 items $(0=$ no, $1=$ yes $)$ about what participants had seen, felt, heard or smelled during or immediately after the disaster. For the level of exposure (sum score) the unit of change was set at one standard deviation (rounded off resulting in 5).

Furthermore, sustained injuries or death of a significant other were assessed $(1=$ no injuries or injuries for which no medical treatment was required and no loss of significant other; $2=$ injuries for which medical treatment by a GP or hospital, or hospitalization was required, or suffering the loss of a significant other). The city council of Enschede designated a geographical area as the official disaster area. Based upon this classification it was registered whether survivors were forced to relocate after the disaster because their homes had been destroyed or seriously damaged $(1=$ no, $2=$ yes $)$.

Depressive symptoms, anxiety symptoms and sleep disturbances were measured at T1 and T2 
using the Dutch version of the Symptom Check List-90-R (SCL-90-R; Arrindell \& Ettema, 1986; Derogatis, 1997). Items have a 5-point Likert scale $(1=$ not at all to $5=$ extremely $)$ and assess the degree of anxiety, depressive symptoms and sleep disturbances over the past 7 days. For the SCL-90-R a score in (or above) the 80th percentile of a Dutch normative sample was used as a cut-off score, indicating a 'high' or 'very high' score (Arrindell \& Ettema, 1986). At all assessment moments, the internal consistencies of both subscales in both groups were excellent (Cronbach's alpha varied from 0.87 to $0 \cdot 94)$.

To assess disaster-related intrusions and avoidance reactions the Dutch version of the Impact of Event Scale (IES; Horowitz et al. 1979; Brom \& Kleber, 1985; Van der Ploeg et al. 2004) was used at T1 and T2. Scores on the 15 items are rated on a four-point Likert scale $(0=$ not at all to $5=$ often $)$ and assess the degree of disaster-related intrusions and avoidance reactions over the past 7 days. A cut-off score of 25 was used to distinguish symptoms at a clinical level, indicating post-traumatic stress disorder (Chemtob et al. 1997). At all measurements, the internal consistencies were excellent (Cronbach's alpha varied from 0.90 to $0 \cdot 94)$.

\section{$G P$ measures}

We used the demographic variables age (in decades) and marital status ( $1=$ not being single, $2=$ being single) from the GP-monitor. ICPC codes P76 (depression), P76.1 (reactive depression), P76.2 (other, not-specified depression) and P03 (feeling down or depressed) were used as the GP-diagnosed counterpart to self-reported depressive symptoms. ICPC-codes P01 (feeling anxiousness, nervousness or tense) and P74 (anxiety disorder or anxiety condition) were used as the diagnosed counterpart to self-reported anxiety symptoms. ICPC-code P06 (insomnia or other sleep disorder) was used as the counterpart to self-reported sleep problems. The ICPC-code P02 'psychological crisis/ temporary stress reactions' constituted the diagnosed counterpart to self-reported posttraumatic stress reactions.

A number of diagnoses and symptoms pertaining to psychological and social problems were clustered into one composite variable.
This so-called psychosocial cluster comprised ICPC codes relating to psychological complaints, fear of developing a somatic disease (e.g. cancer) or a somatic disease with a psychological component (e.g. hyperventilation). This cluster was used as a counterpart to the SCL-90-R total score.

In this paper, only new diagnoses (i.e. new cases) were studied, so 're-diagnoses' from before the disaster were excluded. Thus, a distinction could be made between (1) no contact with a GP; (2) contact with a GP with a specific diagnosis or symptoms corresponding the selfreported problems; and (3) contact with a GP without a specific diagnosis or symptoms corresponding the self-reported problems. The term diagnosis in this paper includes both symptoms and diagnosed disorders.

Furthermore, the number of contacts a patient had with their GP from the disaster until 1 December 2001 was counted.

\section{Analysis}

To study possible differences between the sample and all disaster-affected residents who filled in a questionnaire on T1, we used $t$ tests and $\chi^{2}$. The correspondence between persistent self-reported symptoms and those diagnosed by a GP was analysed by comparing the high IES and SCL-90-R scores with the GPs' diagnoses by means of cross-tabulation. With respect to persistent self-reported mental health problems, four temporal score patterns were discerned (T1-T2): (1) low-low, (2) high-low, (3) low-high, and (4) high-high.

A series of multiple logistic regression analyses were used to test the predictive value for GP-diagnosed counterparts of self-reported mental health problems, the number of GP visits, demographic characteristics and disaster experiences. The self-reported mental health problems were entered in the analyses as: none, not persistent, and persistent. The dependent variable was the specific GPs' reported symptoms and diagnoses. At step 1 (Model 1) selfreported mental health problems and number of GP visits were entered; at step 2 (Model 2) disaster experiences were entered; and at step 3 (Model 3) demographic characteristics [e.g. age, gender, foreign ethnicity, marital status (single) and educational level] were entered into the model. 


\section{RESULTS}

\section{Response}

A total of 1567 disaster-affected residents filled in the questionnaire at $\mathrm{T} 1$ (estimated response $=$ $30 \%$ ) and at T2 1116 survivors responded (response of the second wave was $71 \cdot 2 \%$ ). In total 879 of these respondents were registered in the GP-monitor as well. This constitutes the sample of this study. Of the responders to both the first and second wave $(n=1116), 237$ victims were not registered in the GP-monitor.

The differences between our sample (the group responders at $\mathrm{T} 1$ and $\mathrm{T} 2$ who were also registered in the GP-monitor) and the nonresponders at T2 $(n=688)$ are now described. There were differences in age $(t=-6 \cdot 86$, $p=0.001)$, ethnicity $\left(\chi^{2}=67.70, \quad p<0.001\right)$, gender $\left(\chi^{2}=7.98, p<0.01\right)$, and marital status or longstanding relation $\left(\chi^{2}=9.82, p<0.01\right)$ between the responders (who were also registered in the GP-monitor) and non-responders at the second wave. The former group was older, contained fewer migrants, more males and fewer singles than the latter group (at T2). There were no differences in educational level.

Concerning self-reported disaster-related experiences the two groups did not differ in the percentage of affected respondents who had to be relocated due to the disaster. Furthermore, both groups were equally exposed to the disaster. Concerning psychological problems 2-3 weeks post-disaster (T1), there were no significant differences between responders and non-responders at follow-up. Furthermore nonresponse analyses for the first survey showed that the prevalence rates of mental health problems 2-3 weeks post-disaster were not affected by the non-response (Grievink et al. 2006).

\section{Characteristics of sample}

The mean age of our sample was 44.4 years (s.D. $=15.1) ; 43.9 \%$ were female, $82.6 \%$ were married or living with a partner and $21 \%$ were migrants. For $52 \cdot 1 \%$ the highest level of education was primary school or pre-vocational secondary, for $45.8 \%$ this was pre-university or vocational education or university.

Approximately $10 \%$ of the affected residents reported physical injuries or the loss of a significant other and $19 \cdot 2 \%$ had to be relocated in the aftermath of the disaster. In the 18 months after the disaster the mean number of contacts with a GP was $10 \cdot 7$ (s.D. $=9 \cdot 8$ ).

At $\mathrm{T} 176 \cdot 3 \%$ of the sample showed a high level of self-reported intrusions and avoidance reactions and $46.9 \%$ of the sample reported psychological distress (i.e. high SCL-90-R scores), such as depressive $(54.6 \%)$ or anxiety $(49 \cdot 1 \%)$ symptoms, and sleep disturbances $(55.0 \%)$. At T2 $42.5 \%$ of the affected residents reported a high level of intrusions and avoidance reactions. The percentage of affected residents with psychological distress declined to $34.6 \%$ at T2. Furthermore, at T2 $37.4 \%$ of the sample showed depression symptoms, 33.5\% showed anxiety symptoms and $38.8 \%$ had sleeping disturbances.

\section{Correspondence between persistent self-reported and GP-reported psychological problems}

As shown in Table 1, 169 of the 280 affected residents $(60.4 \%)$ with a high level of selfreported intrusions and avoidance reactions at both $\mathrm{T} 1$ and $\mathrm{T} 2$ were diagnosed with 'psychological crisis/temporary stress reactions', while $36.8 \%$, visiting their GP, received another diagnosis. In $15 \cdot 2 \%(n=24)$ the GP diagnosed 'psychosocial crisis/temporary stress reactions' while the respondents did not show a high level of self-reported intrusions and avoidance reactions at T1 and T2. However, we are not sure if these cases can be considered as 'false positives', because a patient could have been correctly diagnosed for post-traumatic stress in between the two waves. Furthermore patients could have reported intrusions and avoidance reactions to the GP that originated from other traumatic events. The GP did not report any post-traumatic stress symptoms in $68.4 \%$ of the sample responders, with no self-reported intrusions and avoidance reactions on both waves.

The same pattern is observed in the percentages of respondents with a persistent high level of psychological distress (i.e. SCL-90-R total score) and their GP detection rates. The agreement percentage between residents' self-reported psychological distress and GP-diagnoses was $72.6 \%$. Furthermore, the number of patients with high self-reported psychological distress at both times who were not diagnosed with psychological problems by their GP was $23.3 \% \quad(n=34)$. However, the percentage of respondents without self-reported psychological 
Table 1. Rates of general practioners' detection of self-reported post-traumatic stress and general mental health in disaster-affected residents

\begin{tabular}{|c|c|c|c|c|c|c|c|c|}
\hline \multirow{3}{*}{$\begin{array}{l}\text { Self-report } \\
\text { variable pattern }{ }^{a}\end{array}$} & \multicolumn{6}{|c|}{ Contact with GP } & & \\
\hline & \multicolumn{2}{|c|}{$\begin{array}{c}\text { No } \\
\text { contact }\end{array}$} & \multicolumn{2}{|c|}{$\begin{array}{c}\text { Contact: yes } \\
\text { Diagnosed } \\
\text { counterparts }^{\text {b }: \text { yes }}\end{array}$} & \multicolumn{2}{|c|}{$\begin{array}{c}\text { Contact: yes } \\
\text { Diagnosed } \\
\text { counterparts }^{\text {b }: \text { no }}\end{array}$} & \multicolumn{2}{|c|}{$\begin{array}{l}\text { Total group } \\
\quad(n=879)\end{array}$} \\
\hline & $n$ & Row \% & $n$ & Row \% & $n$ & Row \% & $n$ & Column \% \\
\hline \multicolumn{9}{|l|}{ IES } \\
\hline Low-low & 26 & $(16 \cdot 5)$ & 24 & $(15 \cdot 2)$ & 108 & $(68 \cdot 4)$ & 158 & $(21 \cdot 1)$ \\
\hline High-low & 15 & $(5 \cdot 4)$ & 95 & $(34 \cdot 1)$ & 169 & $(60 \cdot 6)$ & 279 & $(37 \cdot 4)$ \\
\hline Low-high & 1 & $(3 \cdot 4)$ & 12 & $(41 \cdot 4)$ & 16 & $(55 \cdot 2)$ & 29 & $(3 \cdot 9)$ \\
\hline High-high & 8 & $(2 \cdot 9)$ & 169 & $(60 \cdot 4)$ & 103 & $(36 \cdot 8)$ & 280 & $(37 \cdot 5)$ \\
\hline Total & 50 & $(6 \cdot 7)$ & 300 & $(40 \cdot 2)$ & 396 & $(53 \cdot 1)$ & 746 & $(100 \cdot 0)$ \\
\hline \multicolumn{9}{|c|}{ SCL-90-R Depression } \\
\hline Low-low & 30 & $(9 \cdot 9)$ & 9 & $(3 \cdot 0)$ & 263 & $(87 \cdot 1)$ & 302 & $(41 \cdot 3)$ \\
\hline High-low & 15 & $(8 \cdot 9)$ & 13 & $(7 \cdot 7)$ & 140 & $(83 \cdot 3)$ & 168 & $(23 \cdot 0)$ \\
\hline Low-high & 3 & $(7 \cdot 0)$ & 3 & $(7 \cdot 0)$ & 37 & $(86 \cdot 0)$ & 43 & $(5 \cdot 9)$ \\
\hline High-high & 5 & $(2 \cdot 3)$ & 32 & $(14 \cdot 7)$ & 181 & $(83 \cdot 0)$ & 218 & $(29 \cdot 8)$ \\
\hline Total & 53 & $(7 \cdot 3)$ & 57 & $(7 \cdot 8)$ & 621 & $(85 \cdot 0)$ & 731 & $(100 \cdot 0)$ \\
\hline \multicolumn{9}{|l|}{ SCL-90-R Anxiety } \\
\hline Low-low & 31 & $(8 \cdot 9)$ & 5 & $(1 \cdot 4)$ & 312 & $(89 \cdot 7)$ & 348 & $(45 \cdot 7)$ \\
\hline High-low & 13 & $(7 \cdot 8)$ & 12 & $(7 \cdot 2)$ & 142 & $(85 \cdot 0)$ & 167 & $(21 \cdot 9)$ \\
\hline Low-high & 5 & $(10 \cdot 9)$ & 4 & $(8 \cdot 7)$ & 37 & $(80 \cdot 4)$ & 46 & $(6 \cdot 1)$ \\
\hline High-high & 5 & $(2 \cdot 5)$ & 40 & $(20 \cdot 0)$ & 155 & $(77 \cdot 5)$ & 200 & $(26 \cdot 3)$ \\
\hline Total & 54 & $(7 \cdot 1)$ & 61 & $(8 \cdot 0)$ & 646 & $(84 \cdot 9)$ & 761 & $(100 \cdot 0)$ \\
\hline \multicolumn{9}{|c|}{ SCL-90-R Sleep disturbances } \\
\hline Low-low & 35 & $(11 \cdot 8)$ & 7 & $(2 \cdot 3)$ & 255 & $(85 \cdot 9)$ & 297 & $(37 \cdot 9)$ \\
\hline High-low & 5 & $(2 \cdot 5)$ & 15 & $(7 \cdot 6)$ & 177 & $(89 \cdot 9)$ & 197 & $(25 \cdot 1)$ \\
\hline Low-high & 2 & $(3 \cdot 2)$ & 7 & $(11 \cdot 1)$ & 54 & $(85 \cdot 7)$ & 63 & $(8 \cdot 0)$ \\
\hline High-high & 12 & $(5 \cdot 3)$ & 46 & $(20 \cdot 3)$ & 169 & $(74 \cdot 5)$ & 227 & $(29 \cdot 0)$ \\
\hline Total & 54 & $(6 \cdot 9)$ & 75 & $(9 \cdot 6)$ & 655 & $(83 \cdot 6)$ & 784 & $(100 \cdot 0)$ \\
\hline \multicolumn{9}{|c|}{ SCL-90-R Total score } \\
\hline Low-low & 34 & $(10 \cdot 7)$ & 117 & $(36 \cdot 8)$ & 167 & $(52 \cdot 5)$ & 318 & $(52 \cdot 6)$ \\
\hline High-low & 8 & $(7 \cdot 5)$ & 57 & $(53 \cdot 3)$ & 42 & $(39 \cdot 3)$ & 107 & $(17 \cdot 7)$ \\
\hline Low-high & 3 & $(9 \cdot 1)$ & 20 & $(60 \cdot 6)$ & 10 & $(30 \cdot 3)$ & 33 & $(5 \cdot 5)$ \\
\hline High-high & 6 & $(4 \cdot 1)$ & 106 & $(72 \cdot 6)$ & 34 & $(23 \cdot 3)$ & 146 & $(24 \cdot 2)$ \\
\hline Total & 51 & $(8 \cdot 4)$ & 300 & $(49 \cdot 7)$ & 253 & $(41 \cdot 9)$ & 604 & $(100 \cdot 0)$ \\
\hline
\end{tabular}

a The pattern is the level of severe symptoms on the questionnaires 2-3 weeks and 18 months post-disaster.

b The GP-recorded counterparts of the relevant psychological problems.

IES, Impact of Event Scale; SCL-90-R, Symptom Check List.

distress, but with a psychological diagnosis from the GP, was $36 \cdot 8 \%$.

The pattern of recognition rates of specific persistent self-reported psychological problems, such as depressive and anxiety symptoms and sleep disturbances, was found to be different. Only $14 \cdot 7 \%(n=32)$ of participants with high depression scores at both times were diagnosed with depressive symptoms by their GP. A similar pattern was found for respondents who had high scores of sleep disturbances or anxiety at both times: about $20 \%$ were diagnosed as such by their GP (sleep disturbances, $n=46 /$ anxiety, $n=40)$. The percentages of participants with high levels of depressive or anxiety symptoms or sleep disturbances that were not diagnosed as such were $83.0 \%, 77 \cdot 5 \%$, and $74.5 \%$ respectively. The percentages of respondents with a GP diagnosis while not having a high self-reported score were small (see Table 1). Furthermore, only less than $5 \%$ of the participants with persistent mental health problems did not visit their GP.

\section{Factors associated with a GP's detection of post-traumatic stress and general mental health}

Multivariate logistic regression analyses revealed that participants with a persistent high level of self-reported intrusions and avoidance reactions who visited their GP frequently were 
Table 2. Results of third model of multivariate logistic regression analyses for factors associated with general practitioners' detection of persistent post-traumatic stress and co-morbid general mental health

\begin{tabular}{|c|c|c|c|c|c|}
\hline & $\begin{array}{l}\text { GP-recorded } \\
\text { avoidance } \\
\text { and intrusions }^{\mathrm{a}} \\
\text { OR }(95 \% \mathrm{CI})\end{array}$ & $\begin{array}{c}\text { GP-recorded } \\
\text { psychosocial } \\
\text { health }^{\mathrm{b}} \\
\text { OR }(95 \% \mathrm{CI})\end{array}$ & $\begin{array}{l}\text { GP-recorded } \\
\text { depressive } \\
\text { symptoms } \\
\text { OR }(95 \% \mathrm{CI})\end{array}$ & $\begin{array}{l}\text { GP-recorded } \\
\text { anxiety } \\
\text { symptoms }^{d} \\
\text { OR }(95 \% \mathrm{CI})\end{array}$ & $\begin{array}{l}\text { GP-recorded } \\
\text { sleep } \\
\text { disturbances } \\
\text { OR }(95 \% \mathrm{CI})\end{array}$ \\
\hline Contact with GP & $1 \cdot 07(1 \cdot 05-1 \cdot 10)^{* * *}$ & $1 \cdot 11(1 \cdot 08-1 \cdot 15)^{* * *}$ & $1.08(1 \cdot 05-1 \cdot 12)^{* * *}$ & $1 \cdot 03(1 \cdot 00-1 \cdot 06)^{*}$ & $1 \cdot 03(1 \cdot 01-1 \cdot 06)^{* *}$ \\
\hline Corresponding questionnaire & $1 \cdot 80(1 \cdot 37-2 \cdot 36) * * *$ & $1.62(1 \cdot 25-2 \cdot 11)^{* * *}$ & $1.99(1.29-3.07)^{* *}$ & $3 \cdot 47(2 \cdot 19-5 \cdot 50) * * *$ & $2.89(1.95-4.28) * * *$ \\
\hline Relocation & $2 \cdot 33(1.48-3 \cdot 97) * * *$ & $2 \cdot 23(1 \cdot 28-3 \cdot 87)^{* *}$ & $0 \cdot 95(0 \cdot 43-2 \cdot 07)$ & $1 \cdot 05(0 \cdot 51-2 \cdot 15)$ & $1.09(0 \cdot 59-1.99)$ \\
\hline $\begin{array}{l}\text { Injuries or loss of } \\
\text { significant other }\end{array}$ & $2 \cdot 00(1 \cdot 12-3 \cdot 55)^{* *}$ & $1 \cdot 55(0 \cdot 77-3 \cdot 10)$ & $1 \cdot 13(0 \cdot 47-2 \cdot 73)$ & $2 \cdot 45(1 \cdot 11-5 \cdot 42)^{*}$ & $0 \cdot 96(0 \cdot 44-2 \cdot 10)$ \\
\hline Ethnicity (migrants) & $0 \cdot 70(0 \cdot 42-1 \cdot 52)$ & $0 \cdot 77(0 \cdot 43-1 \cdot 38)$ & $0 \cdot 65(0 \cdot 28-1 \cdot 51)$ & $0 \cdot 78(0 \cdot 37-1 \cdot 63)$ & $0.95(0.51-1 \cdot 77)$ \\
\hline Gender (females) & $1 \cdot 13(0 \cdot 78-1 \cdot 64)$ & $1 \cdot 36(0 \cdot 91-2 \cdot 04)$ & $1 \cdot 16(0 \cdot 59-2 \cdot 27)$ & $2.90(1.39-6 \cdot 02)^{* *}$ & $1 \cdot 27(0 \cdot 73-2 \cdot 21)$ \\
\hline Age (older) & $1 \cdot 00(0 \cdot 87-1 \cdot 14)$ & $1 \cdot 01(0 \cdot 87-1 \cdot 17)$ & $0.98(0 \cdot 77-1 \cdot 25)$ & $1 \cdot 04(0 \cdot 82-1 \cdot 31)$ & $0 \cdot 90(0 \cdot 74-1 \cdot 10)$ \\
\hline Marital status (single) & $1 \cdot 18(0 \cdot 73-1 \cdot 91)$ & $1 \cdot 47(0 \cdot 87-2 \cdot 48)$ & $1 \cdot 14(0 \cdot 53-2 \cdot 47)$ & $1 \cdot 36(0.65-2 \cdot 87)$ & $1 \cdot 04(0 \cdot 54-2 \cdot 00)$ \\
\hline Educational level (high) & $1 \cdot 05(0 \cdot 71-1 \cdot 53)$ & $0 \cdot 80(0 \cdot 52-1 \cdot 22)$ & $3 \cdot 42(1 \cdot 63-7 \cdot 17)^{* *}$ & $0 \cdot 68(0 \cdot 34-1 \cdot 36)$ & $1 \cdot 04(0 \cdot 60-1 \cdot 82)$ \\
\hline
\end{tabular}

\footnotetext{
a Corresponding questionnaire is IES.

b Corresponding questionnaire is the SCL-90-R total score.

c Corresponding questionnaire is the Depression subscale of the SCL-90-R.

d Corresponding questionnaire is the Anxiety subscale of the SCL-90-R.

e Corresponding questionnaire is the Sleep Disturbances subscale of the SCL-90-R.

OR, Odds ratio; $\mathrm{CI}$, confidence interval.

$* p<0 \cdot 05, * * p<0 \cdot 01, * * * p<0 \cdot 001$.
}

more likely to receive a diagnosis for 'psychosocial crisis/temporary stress reactions' (Model $\left.1: \Delta \chi^{2}=41 \cdot 1, p=0 \cdot 001\right)$. Secondly (Model 2), we entered three disaster-related experiences in the model. Being relocated after the disaster, the degree of exposure to the disaster, and sustaining physical injuries or losing a significant other were significantly associated with GP-reported post-traumatic stress (Model 2: $\Delta \chi^{2}=37 \cdot 0$, $p=0 \cdot 001$ ). Demographic characteristics (Model 3 ) did not show effects on the registration of post-traumatic stress by the GP, as shown in Table 2. The magnitude of the odds ratios was hardly affected (in Table 2 only the results of the third model of each mental health problem are shown).

Concerning the GPs' recordings of psychological problems, the first two models are significant as well (Model 1: $\Delta \chi^{2}=28 \cdot 2, p=0 \cdot 001$; Model 2: $\left.\Delta \chi^{2}=21 \cdot 8, p=0 \cdot 001\right)$. In addition to the total SCL-90-R score of the participants, the number of contacts with a GP and disasterrelated experiences, such as relocation and the level of exposure to the disaster, were significantly associated with the registration of psychological problems by a GP. However, demographic factors and injuries or loss of significant others did not influence the GPs' recordings of general mental health.
Regarding specific psychological problems, the level of self-reported depressive symptoms, anxiety and sleep disturbances and the number of visits paid to a GP predicted the GPs' recording the corresponding diagnosis/symptoms (Model 1 depressive symptoms: $\Delta \chi^{2}=10 \cdot 2$, $p=0.01$; Model 1 anxiety: $\Delta \chi^{2}=34 \cdot 4, p=0.001$; Model 1 sleep disturbances: $\Delta \chi^{2}=34 \cdot 5, p=$ $0 \cdot 001)$. In contrast to post-traumatic intrusions and avoidances and psychological problems in general, disaster-related experiences were of little importance for the specific psychological problems.

As shown in Table 2 the third step (Model 3) significantly contributed to GP's recording of depression and anxiety symptoms. A higher level of education increased the GPs' registration of depressive symptoms while being a female victim increased the registration for anxiety symptoms.

Compared with self-reported psychological problems, the number of contacts and disasterrelated experiences, demographic factors were of little importance in this study. For example, having a foreign ethnic background did not significantly influence the GPs' reports concerning mental health problems.

In addition, we re-analysed our data with an IES cut-off score of 35 . As expected, there were 
differences in prevalences between both cut-off scores on both $\mathrm{T} 1$ and $\mathrm{T} 2$. With a cut-off of 25 and with the cut-off of $35,280(37 \cdot 5 \%)$ and $164(22.0 \%)$ respectively had high scores on both T1 and T2. However, the correspondence rate was hardly affected by the higher cut-off scores. With cut-off score 25 a high-high score on the IES corresponded in $60.4 \%$ with the GP-diagnosis and did not correspond in $36.8 \%$ of the group with the GP-diagnosis. In the case of the cut-off score of 35 these percentages are $62.8 \%$ (correspondence) and $34.1 \%$ (noncorrespondence) respectively. Furthermore, the magnitude of the odds ratios was not affected.

\section{DISCUSSION}

The correspondence rate of the GP-reported and self-reported persistent psychological problems was $73 \%$ in the period 1.5 years postdisaster. Less than $5 \%$ of the participants with high levels of mental health problems on both waves did not visit their GP. Most affected residents with persistent psychological problems had contact with the GP.

Compared with the recognition of depression in the general population (36-62\%: Van der Pas \& Verhaak, 1998; Kessler et al. 1999; Borowsky et al. 2000; Saltini et al. 2004) the correspondence between self-reported and GP-reported psychological problems appears reasonably high. However, studying the symptoms specifically the correspondence rapidly diminished. With a correspondence rate of $60 \%$, disaster-related intrusions and avoidance reactions were the specific symptoms most detected. However, GPs detected persistent depression, anxiety symptoms and sleep disturbances in less than a fifth of the cases. Nonpersistent mental health problems were poorly detected. How can the different correspondence rates be explained?

First, GPs are generally educated and trained physicians. They have to be able to recognize both mental health problems and physical problems, to give natal and palliative care, and so on. For a GP it is sufficient to recognize mental health problems or disorders in general, so that they can refer their patient to specialized mental heath services if necessary.

Secondly, different sources of data collection may explain the differences in correspondence rates for specific psychological problems. The self-report questionnaires assess psychological problems in a structured way. We cannot expect a GP to take an extensive psychological anamnesis in a limited period. In most cases a GP writes down a few codes, which probably reflects the most important or more pronounced problem. Furthermore, the different threshold that is being used by the GP compared with the threshold of the questionnaire may account for the variation between self-reported symptoms and GP-diagnosis. This is partly reflected in the relatively low correspondence rates with respect to non-persistent psychological problems.

Additionally, when physical symptoms are also discussed during the consultation, patients are less likely to have their depressive symptoms recognized (Tylee, 1999). Some patients with psychological problems tend to present their somatic symptoms first and only mention their psychological problems late in the consultation (Tylee, 1999). Kessler and colleagues (1999) showed that the different styles in attribution of symptoms were associated with the detection rates of anxiety and depression. Patients who explained the cause of their problems in a psychological way were more likely to get a psychological diagnosis than patients who had a normalizing attribution-style. A normalizing style of attribution had the opposite effect: the stronger a patient's tendency to normalize or minimize his or her symptoms, the less likely they were to be considered depressed or anxious by their GP (Kessler et al. 1999).

Our results suggest that GPs were more likely to identify psychological problems in patients with high levels of self-reported psychological distress who paid a higher number of visits to them. The same pattern is seen with regard to depressive problems, anxiety and sleep disturbances.

We found no indications that the GPs are influenced by individual patient characteristics (e.g. age, marital status and gender) in diagnosing mental health problems. Our finding that immigrants in our sample were not relatively under- or over-diagnosed complies with other studies (e.g. Borowsky et al. 2000; Bhui et al. 2001; Bhui \& Bhugra, 2002; Maginn et al. 2004). Unfortunately, we were not able to distinguish between subgroups of immigrants, owing to the low sample size. Previous studies 
revealed differences between ethnic minority groups (Maginn et al. 2004).

However, survivors who were forced to relocate and survivors with high disaster exposure were more likely to be registered by the GP as suffering from psychological crisis/temporary stress reactions and psychosocial problems than other survivors. This finding indicates that the GP diagnosis is partly affected by the survivors status (whether he or she was relocated or highly exposed). It is unknown whether this can be attributed to bias in the GP (for example because the GP was aware of this status and therefore was more sensitive to these problems), reluctance of survivors who were less exposed to the disaster to speak about their post-disaster mental health problems or an interaction between both.

A few study limitations should be noted. With regard to the longitudinal study among the affected residents, the estimated response at T1 was relatively low $(30 \%)$ with an overrepresentation of women and immigrants in comparison with the overall population affected by the disaster. However, we found no indication that this selection affected the prevalence rates of problems at $\mathrm{T} 1$.

In this study no standardized clinical interviews (such as CIDI) were conducted and the measurement of psychological distress by questionnaires was limited to two moments.

Approximately one-third of the participants who did not express any psychological distress at 2-3 weeks and at 18 months post-disaster on the self-report questionnaires were diagnosed as suffering from psychological problems by their GP. We are not sure if these cases can be considered as 'false positives'. There is a chance that a patient could have been correctly diagnosed for psychological problems in between the two waves.

In conclusion, the results of our research indicate that GPs function as reasonably good gatekeepers for mental health services after a disaster: less than $5 \%$ of the participants with persistent psychological problems did not visit the GP. The correspondence between GP-reported and self-reported post-disaster mental health problems was hardly affected by gender, ethnicity or education. Presumably, GPs pay special attention to the affected victims' psychological health after such a disaster. How- ever, GPs do have to be aware that information about the disaster experiences of their patient may affect their diagnosis.

\section{ACKNOWLEDGEMENTS}

We gratefully acknowledge the contribution of affected residents and their general practitioners. In addition, we would like to acknowledge Dr Joris Yzermans and Professor Dr Berthold Gersons for their valuable contribution. This research was funded by a grant from the ministry of Public Health, Welfare and Sports in The Netherlands.

\section{DECLARATION OF INTEREST}

None.

\section{REFERENCES}

Akker, M., Mol, S. S. L., Metsemakers, J. F. M., Dinant, G.-J. \& Knottnerus, J. A. (2001). Barriers in the care of patients who have experienced a traumatic event: the perspective of general practice. Family Practice 18, 214-216.

Arrindell, W. A. \& Ettema, J. M. H. (1986). SCL-90: Handleiding bij een multidimensionele psychopathologie indicator [Manual for a multidimensional psychopathology indicator]. Swets and Zeitlinger: Lisse, The Netherlands.

Başoğlu, M., Kılıç, C., Şalcıŏ̆lu, E. \& Livanou, M. (2004). Prevalence of post-traumatic stress disorder and co morbid depression in earthquake survivors in Turkey: an epidemiological study. Journal of Traumatic Stress 17, 133-141.

Başoğlu, M., Şalcığlu, E., Livanou, M., Kalender, D. \& Acar, G. (2005). Single-session behavioural treatment of earthquake-related post-traumatic stress disorder: a randomized waiting list controlled trial. Journal of Traumatic Stress 18, 1-11.

Bhui, K. \& Bhugra, D. (2002). Mental illness in Black and Asian ethnic minorities: pathways to care and outcomes. Advances in Psychiatric Treatment 8, 26-33.

Bhui, K., Bhugra, D., Goldberg, D., Dunn, G. \& Desai, M. (2001). Cultural influences on the prevalence of common mental disorder, general practitioners' assessments and help-seeking among Punjabi and English people visiting their general practitioner. Psychological Medicine 31, 815-825.

Borowsky, S. J., Rubenstein, L. V., Meredith, L. S., Camp, P., Jackson-Triche, M. \& Wellis, K. B. (2000). Who is at risk of nondetection of mental health problems in primary care? Journal of General Internal Medicine 15, 381-388.

Bower, P., West, R., Tylee, A. \& Hann, M. (2000). Symptom attribution and the recognition of psychiatric morbidity. Journal of Psychosomatic Research 48, 157-160.

Breslau, N., Davis, G. C., Peterson, E. L. \& Schultz, L. R. (2000). A second look at comorbidity in victims of trauma: the posttraumatic stress disorder-major depression connection. Biological Psychiatry 48, 902-909.

Breslau, N., Kessler, R. C., Chilcoat, H. D., Schultz, L. R., Davis, G. D. \& Andreski, P. (1998). Trauma and post-traumatic stress disorder in the community. The 1996 Detroit area survey of trauma. Archives of General Psychiatry 55, 626-632.

Brewin, C. R. \& Holmes, E. A. (2003). Psychological theories of post-traumatic stress disorder. Clinical Psychology Review 23, 339-376. 
Brom, D. \& Kleber, R. J. (1985). De Schok Verwerkings Lijst [The Dutch version of the Impact of Event Scale]. Nederlands Tijdschrift voor Psychologie 40, 164-168.

Callahan, E. J., Bertakis, K. D., Azari, R., Robbins, J. A., Helms, L. J. \& Chang, D. W. (2000). The influence of patient age on primary care resident physician-patient interaction. Journal of the American Geriatrics Society 48, 30-35.

Chemtob, C. M., Tomas, S., Law, W. \& Cremniter, D. (1997). Post disaster psychosocial intervention: a field study of the impact of debriefing on psychological distress. American Journal of Psychiatry 154, 415-417.

Creamer, M. (1995). A cognitive processing formulation of posttrauma reactions. In: Beyond Trauma: Cultural and Societal Dynamics (ed. R. J. Kleber, C. R. Figley and B. P. R. Gersons), pp. 55-73. Plenum Press: New York.

Del Piccolo, L., Saltini, A. \& Zimmermann, C. (1998). Which patients talk about stressful life events and social problems to the general practitioner? Psychological Medicine 28, 1289-1299.

Derogatis, L. R. (1997). SCL-90-R: Administration, Scoring and Procedures Manual-I for the R(evised) Version. Johns Hopkins University School of Medicine, Clinical Psychometrics Research Unit: Baltimore, MD.

Donker, G. A., Yzermans, C. J., Spreeuwenberg, P. \& Van der Zee, J. (2002). Symptoms attribution after a plane crash: comparison between self-reported symptoms and GP records. British Journal of General Practice 52, 917-922.

Foa, E. B., Zoellner, L. A. \& Feeny, N. C. (2006). An evaluation of three brief programs for facilitating recovery after assault. Journal of Traumatic Stress 19, 29-43.

Galea, S., Namdi, A. \& Vlahov, D. (2005). The epidemiology of posttraumatic stress disorder after disasters. Epidemiologic Reviews 27, 78-91.

Grievink, L., Van der Velden, P. G., Yzermans, C. J., Roorda, J. \& Stellato, R. K. (2006). The importance of estimating selection bias on prevalence estimates shortly after a disaster. Annals of Epidemiology 16, 782-788.

Horowitz, M. J. (1976). Stress Response Syndromes. Jason Aronson Oxford.

Horowitz, M. J., Wilner, N. \& Alvares, K. M. (1979). The impact of event scale: a measure of subjective stress. Psychosomatic Medicine 41, 209-218.

ICPC-2 (1998). International Classification of Primary Care (2nd edn). Prepared by the International Classification Committee of WONCA. Oxford: Oxford University Press

Kessler, D., Lloyd, K., Lewis, G. \& Pereira Gray, D. (1999). Crosssectional study of symptom attribution and recognition of depression and anxiety in primary care. British Medical Journal 318, 436-440.

Lamberts, H. \& Woods, M. (1987). The International Classification of Primary Care. Oxford: Oxford University Press.

Maginn, S., Boardman, A. P., Craig, T. K. J., Haddad, M., Heath, G. \& Stott, J. (2004). The detection of psychological problems by general practitioners: influence of ethnicity and other demographic variables. Social Psychiatry and Psychiatric Epidemiology 39, 464-471.

Mol, S. S. L., Dinant, G.-J., Vilters-van Montfoort, P. A. P., Metsemakers, J. F. M., Van den Akker, M., Arntz, A. \& Knottnerus, J. A. (2002). Traumatic events in a general population: the patient's perspective. Family Practice 19, 390-396.
Norris, F. H., Friedman, M. J., Watson, P. J., Byrne, C. M., Diaz, E. \& Kaniasty, K. (2002). 60000 disaster victims speak: Part I. An empirical review of the empirical literature, 1981-2001. Psychiatry 65, 207-239.

Nuyen, J., Volkers, A. C., Verhaak, P. F. M., Schellevis, F. G., Groenewegen, P. P. \& Van den Bos, G. A. M. (2005). Accuracy of diagnosing depression in primary care: the impact of chronic somatic and psychiatric co-morbidity. Psychological Medicine 35, $1185-1195$.

Roorda, J., Van Stiphout, W. A. \& Huijsman-Rubingh, R. R. R. (2004). Post-disaster health effects: strategies for investigation and data-collection: experiences from the Enschede firework disaster. Journal of Epidemiology and Community Health $\mathbf{5 8}$, 982-987.

Saltini, A., Mazzi, M. A., Del Piccolo, L. \& Zimmerman, C. (2004). Decisional strategies for attribution of emotional distress in primary care. Psychological Medicine 34, 729-739.

Stuber, J., Galea, S., Boscarino, J. A. \& Schlesinger, M. (2006). Was there unmet mental health need after the September 11, 2001 terrorist attacks? Social Psychiatry and Psychiatric Epidemiology 41, 230-240.

Thompson, C., Ostler, K., Peveler, R. C., Baker, N. \& Kinmonth, A.-N. (2001). Dimensional perspective on the recognition of depressive symptoms in primary care: the Hampshire Depression Project 3. British Journal of Psychiatry 179, 317-323.

Tylee, A. (1999). Depression in the community: physicians and patient perspective. Journal of Clinical Psychology 60, 12-16.

Van der Pas, M. \& Verhaak, P. F. M. (1998). Communication in general practice: recognition and treatment of mental illness. Patient Education and Counseling 33, 97-112.

Van der Ploeg, E., Mooren, T., Kleber, R. J., Van der Velden, P. G. \& Brom, D. (2004). Construct validation of the Dutch version of the Impact of Event Scale. Psychological Assessment 16, 16-26.

Van der Velden, P. G., Grievink, L., Kleber, R. J., Drogendijk, A. N., Roskam, A. J. R., Marcelissen, F. G. H., Olff, M., Meewisse, M. L. \& Gersons, B. P. R. (2006a). Post disaster mental health problems and the utilization of mental health services: a four-year longitudinal comparative study. Administration and Policy in Mental Health and Mental Health Services Research 33, 279-88.

Van der Velden, P. G., Kleber, R. J., Christiaanse, B., Roskam, A. J. R., Gersons, B. P. R., Marcelissen, F. G. H., Drogendijk, A. N., Grievink, L., Olff, M. \& Meewisse, M. L. $(2006 b)$. The predictive value of peritraumatic dissociation for post-disaster intrusions and avoidance reactions and PTSD severity: a 4-year prospective study. Journal of Traumatic Stress 19, 493-506.

Van Kamp, I., Van der Velden, P. G., Stellato, R., Roorda, J., Van Loon, J., Kleber, R. J., Gersons, B. P. R. \& Lebret, E. (2005). Physical and mental health shortly after a disaster: first results from the Enschede firework disaster study. European Journal of Public Health 16, 252-258.

Yang, Y. K., Yeh, T. L., Chen, C. C., Lee, C. K., Lee, I. H., Lee, L.-C \& Jeffries, K. J. (2003). Psychiatric morbidity and post-traumatic symptoms among earthquake victims in primary care. General Hospital Psychiatry 25, 253-261.

Yzermans, C. J., Donker, G. A., Kerssens, J. J., Dirkzwager, A. J. E., Soeteman, R. J. H. \& Ten Veen, P. M. H. (2005). Health problems of victims before and after disaster: a longitudinal study in general practice. International Journal of Epidemiology $\mathbf{3 4}$ 810-819. 